J. Lake Sci.(湖泊科学) , 2018, 30(4): 957-966

DOI 10. 18307/2018. 0409

(c) 2018 by Journal of Lake Sciences

\title{
碳氮稳定同位素示踪鄱阳湖流域蚌湖丰水期的氮污染
}

\author{
梁 越 $^{1}$, 肖化云 ${ }^{1 * *}$, 刘小真 ${ }^{2 * *}$, 胡倩倩 ${ }^{1}$, 谢亚军 $^{1}$, 曹彦圣 $^{1}$, 丁 新航 $^{1}$ \\ ( 1 : 东华理工大学江西省大气污染成因与控制重点实验室,核资源与环境国家重点实验室培育基地,水资源与环境工程 \\ 学院,南昌 330013) \\ (2:南昌大学资源环境与化工学院,鄱阳湖环境与资源利用教育部重点实验室,南昌 330047)
}

\begin{abstract}
摘 要: 鄱阳湖边缘深水区是鄱阳湖水位上涨时扩散而成的低洼湖区, 通过对其一典型边缘湖泊一一蚌湖丰水期的氮浓 度和同位素特征值的检测, 分析这类洪泛湖泊在水位最高时期水体颗粒有机质及无机氮的氮同位素变化特征,并识别氮 污染来源及转化途径. 结果表明: 6 月悬浮颗粒有机质碳氮同位素值 $\left(\delta^{13} \mathrm{C}:-26.7 \% 0 \sim-23.7 \% 0, \delta^{15} \mathrm{~N}: 2.6 \% 0 \sim 6.2 \% 0\right)$ 介于 土壤有机质 $\left(\delta^{13} \mathrm{C}:-25.21 \% 0 \pm 0.52 \% 0, \delta^{15} \mathrm{~N}: 3.79 \% 0 \pm 0.37 \% 0\right)$ 和水生植物的碳氮同位素值 $\left(\delta^{13} \mathrm{C}:-28.8 \% 0 \sim-24.9 \%\right.$, $\left.\delta^{15} \mathrm{~N}: 5.3 \% 0 \sim 8.2 \% 0\right)$ 之间. 7 月相比于 6 月,降低的 $\delta^{13} \mathrm{C}(-27.6 \% 0 \sim-23.2 \% 0)$ 和升高的 $\delta^{15} \mathrm{~N}(4.3 \% 0 \sim 7.7 \% 0)$ 表明暴雨冲刷 带来更多的周边陆地碎屑输人. 无机氮在 6 月以铵态氮 $\left(\mathrm{NH}_{4}^{+}-\mathrm{N}\right)$ 为主要形态, 7 月以硝态氮 $\left(\mathrm{NO}_{3}^{-}-\mathrm{N}\right)$ 为主要形态. 6 月 $\delta^{15} \mathrm{NH}_{4}^{+}$较负的特征值 $(-18.6 \% 0 \pm 5.2 \% 0)$ 表明铵态氮主要来源于雨水, 硝态氮 $\left(\delta^{15} \mathrm{NO}_{3}^{-}: 1.4 \% 0 \pm 3.0 \% 0\right)$ 主要来源于农业化肥 和雨水. 7 月相比于 6 月, 铵态氮和硝态氮的浓度和同位素值都大幅升高 (分别升高了 0.3 和 2 倍, $6 \% 0$ 和 $3 \%$ ) , 是暴雨冲 刷陆地使农业化肥、城镇生活废水和畜禽养殖废水输人的结果. 水生植物的 $\delta^{15} \mathrm{~N}$ 在 7 月 $(8.8 \% 0 \pm 1.1 \% 0)$ 相比于 6 月 $(6.6 \% 0 \pm 1.1 \% 0)$ 也升高了较多, 是由于水生植物吸收了更高 $\delta^{15} \mathrm{~N}$ 废水无机氮的结果. 通过颗粒有机质和无机氮的 $\delta^{15} \mathrm{~N}$ 分 析可知, 湖区水体氮的矿化作用和硝化作用较强, 藻类对湖泊的内源氮贡献较弱, 沿河湖的畜禽养殖在暴雨时对水域污 染的威胁较大. 本研究提供了洪泛湖泊氮污染治理的科学依据.
\end{abstract}

关键词: 碳氮稳定同位素;氮污染; 鄱阳湖;蚌湖; 丰水期

\section{Carbon and nitrogen stable isotopes tracing nitrogen pollution in major flooding season in Lake Bang, Lake Poyang Basin}

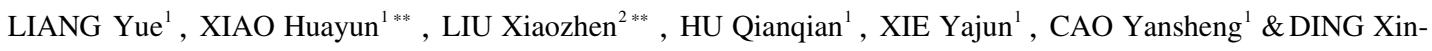
hang $^{1}$
(1: Jiangxi Province Key Laboratory of the Causes and Control of Atmospheric Pollution, State Key Laboratory Breeding Base of Nuclear Resources and Environment, School of Water Resources \& Environmental Engineering, East China University of Technology, Nanchang 330013, P.R.China)

(2: Key Laboratory of Poyang Lake Environment and Resource Utilization, Ministry of Education, School of Resources Environmental \& Chemical Engineering, Nanchang University, Nanchang 330047, P.R.China)

\footnotetext{
Abstract: The edge low-lying regions of are deep-water lakes when water levels rise and spread. We analyzed the changing characteristics of nitrogen stable isotope values of the particle organic matter and inorganic nitrogen during major flooding seasons in Bang Lake, one of the edge-lake of , and discriminated the origins and transformations of nitrogen pollution. The results showed that carbon and nitrogen stable isotopes value $\left(\delta^{13} \mathrm{C}, \delta^{15} \mathrm{~N}\right)$ of suspended particle organic matter in June were $-26.7 \% 0--23.7 \%$ and $2.6 \% 0-6.2 \%$, respectively, which were in the range of those of soil organic matter $\left(-25.21 \%{ }_{0} \pm 0.52 \% 0\right.$ and $3.79 \% \%_{0} \pm 0.37 \%$, respectively) and those of water plant $\left(-28.8 \%--24.9 \%\right.$ and $5.3 \%_{0}-8.2 \%$, respectively $)$. The decreasing $\delta^{13} \mathrm{C}(-27.6 \% 0-$

* 国家自然科学基金项目(41563001)、国家重大研究与开发项目 (2016YTA0601000)、东华理工大学核资源与环境 国家重点实验室培育基地自主基金项目 (Z1610) 和东华理工大学江西省大气污染成因与控制重点实验室开放基 金项目 (AE1602, DHBK2015326) 联合资助. 2017-11-08 收稿; 2017-12-04 收修改稿. 梁越 (1974 ), 女, 博士; E-mail: liangyue@ ecit.cn.

** 通信作者; E-mail: xiaohuayun@ vip.skleg.cn, liuxiaozhen@ ncu.edu.cn.
} 
$-23.2 \% 0)$ and the rising $\delta^{15} \mathrm{~N}(4.3 \% 0-7.7 \% 0)$ in July relative to June showed more terrestrial detritus input besides soil organic matter and water plant when rainstorm washes. $\mathrm{NH}_{4}^{+}-\mathrm{N}$ was main form of inorganic nitrogen in June whereas $\mathrm{NO}_{3}^{-}-\mathrm{N}$ was main form of inorganic nitrogen in July. The more negative $\delta^{15} \mathrm{NH}_{4}^{+}(-18.6 \% 0 \pm 5.2 \% 0)$ showed ammonia-nitrogen mainly came from rain, and nitrate-nitrogen $\left(\delta^{15} \mathrm{NO}_{3}^{-}: 1.4 \% \pm 3.0 \%\right.$ ) mainly from agricultural fertilizer and rain. The concentrations and isotopic values of $\mathrm{NH}_{4}^{+}-\mathrm{N}$ and $\mathrm{NO}_{3}^{-}-\mathrm{N}$ had much more increasing ( 0.3 and 2 times, $6 \%$ and 3\%o, respectively) in July than June, which were possible from livelihood wastewater and livestock and poultry breeding wastewater under rainstorm washing. $\delta^{15} \mathrm{~N}$ of aquatic plant had more increasing in July $\left(8.8 \% \pm \pm 1.1 \%\right.$ ) than June $\left(6.6 \% \pm 1.1 \%\right.$ ) due to aquatic plant absorbing high $\delta^{15} \mathrm{~N}$ of wastewater. The mineralization and nitrification of nitrogen in the lake were strong by $\delta{ }^{15} \mathrm{~N}$ analysis, and alga made little contribution to internal nitrogen sources in flooding seasons. It was great threaten to watersheds pollution to livestock and poultry breeding along the bank of river and lake under rainstorm. This study can help to control nitrogen pollution of flooding lakes.

Keywords: Carbon and nitrogen stable isotopes; nitrogen pollution; Lake Poyang; Lake Bang; flooding season

氮污染一直是水环境问题研究的热点, 过量的氮输人引起湖泊富营养化、水生生物死亡和湖水不能利 用等一系列水环境问题 ${ }^{[-2]}$. 湖泊氮的来源具有多样性, 分为内源和外源, 内源通常是湖泊内部水生生物碎 屑和沉积物孔隙水释放等; 外源则十分广泛, 有大气干湿沉降、河流径流带来的土壤有机质、陆地植物碎屑、 农业粪肥、生活污物和工业排污等 ${ }^{[3]}$. 湖泊氮的循环转化过程也较复杂, 主要为有机质矿化分解、无机氮的 硝化与反硝化作用等生物地球化学过程.

碳氮稳定同位素技术可以较好地示踪湖泊氮的来源, 并可大致作为判别氮的贡献和转化过程的理论依 据 ${ }^{[4-6]}$. 因为不同形态和来源的碳或氮具有相异的同位素值, 并且在转化过程中具有同位素分馏效应. 比如 农业输人河流硝态氮同位素组成 $(-4 \% 0 \sim 4 \% 0)$ 低于城市、工业污染河流硝态氮同位素值 $(10 \% 0 \sim 25 \% 0)^{[7]}$. 研 究表明人为氮源的过量输人改变了水环境的性质, 研究氮同位素组成 $\left(\delta^{15} \mathrm{~N}\right)$ 的变化可以有效地示踪受人类 活动及污水影响的水环境的过程和变化 ${ }^{[5,8-9]}$. 颗粒有机质氮的来源通常是利用碳氮稳定同位素结合碳氮比 $\left(\delta^{13} \mathrm{C} 、 \delta^{15} \mathrm{~N}\right.$ 和 $\mathrm{C} / \mathrm{N}$ 比) 来判别 ${ }^{[10]}, \mathrm{C} / \mathrm{N}$ 比也作为有机质分解程度的指示剂,一般随分解程度的增加而减 小 ${ }^{[11]}$, 水体中无机氮的来源及转化可以利用铵态氮同位素 $\left(\delta^{15} \mathrm{NH}_{4}^{+}\right)$和硝态氮同位素 $\left(\delta^{15} \mathrm{NO}_{3}^{-}\right)$来示踪 ${ }^{[12-13]}$.

不同地域、时空变化和不同类型的水域应用同位素的方法研究氮来源的结果差异较大, 具有重要的研 究意义. 例如, 太湖东部氮污染的主要氮源为土壤有机氮、大气沉降及围网养殖 ${ }^{[14]}$; 太湖北部氮污染的主要 氮源为生活污水与粪便 ${ }^{[15]}$; 太湖西部氮污染在枯水期的主要氮源为农业化肥, 在丰水期主要为生活污 水 ${ }^{[16]}$. 鄱阳湖是长江中下游的重要湖泊之一,近些年来王毛兰等 ${ }^{[17-19]}$ 应用同位素方法对鄱阳湖主干和人湖 口河道的颗粒有机质进行了研究, 表明不同湖水段, 有机质氮含量和氮同位素组成有较大的时空差异, 是受 当地土地利用类型和污染类型不同所致, 是氮污染物不同来源的有效指示. 鄱阳湖也是一个过水性洪泛湖 泊, 在年内水位差异很大 $(8 \sim 12 \mathrm{~m}$ ), 丰水期的水面积往往是枯水期的十几倍以上( 江西省水文局星子站水 位), 鄱阳湖的边缘湖区即是水位上涨扩散而成的水域 (一般在 5-9 月), 对于这种边缘类型湖泊氮的来源 和转化过程研究较少. 蚌湖即为鄱阳湖典型的边缘深水区, 位于鄱阳湖两大支流 (赣江北支和修河) 人湖口 附近, 枯水期秋、冬季节是一个湿地,除了少量降雨外, 几乎没有外来水源; 丰水期夏季便是周边水域扩散而 成且水面积大了几十倍的湖泊, 水流相对缓慢, 污染物来源广泛而复杂, 相对较弱的水交换能力有利于营养 元素和污染物的蓄积, 易产生富营养化现象 ${ }^{[20-21]}$. 本研究将利用稳定同位素示踪蚌湖在丰水期多种形式氮污 染的来源, 包括 $\delta^{13} \mathrm{C} 、 \delta^{15} \mathrm{~N}$ 结合 $\mathrm{C} / \mathrm{N}$ 比示踪表层沉积物、水生植物和悬浮颗粒有机氮的来源; $\delta^{15} \mathrm{NH}_{4}^{+}$和 $\delta^{15} \mathrm{NO}_{3}^{-}$ 示踪铵态氮和硝态氮的来源及可能发生的转化过程, 为这种洪泛类型湖泊的氮污染治理提供科学依据.

\section{1 材料与方法}

\section{1 研究区域与样品采集}

蚌湖 $\left(29.268^{\circ} \sim 29.271^{\circ} \mathrm{N}, 115.934^{\circ} \sim 115.979^{\circ} \mathrm{E}\right)$ 位于江西省星子县南部和吴城镇北面之间, 起始于赣 江北支与修河人鄱阳湖口附近, 是鄱阳湖边缘的一个天然湖泊, 面积约 $80 \mathrm{~km}^{2}$. 蚌湖和其周边水域 (贑江、修 河人湖口以及鄱阳湖主体) 之间存在一天然堤坝 (图 1). 丰水期周边水域越过堤坝进人蚌湖, 实际上它们已 成为一整体水域,呈现高水位一致性. 


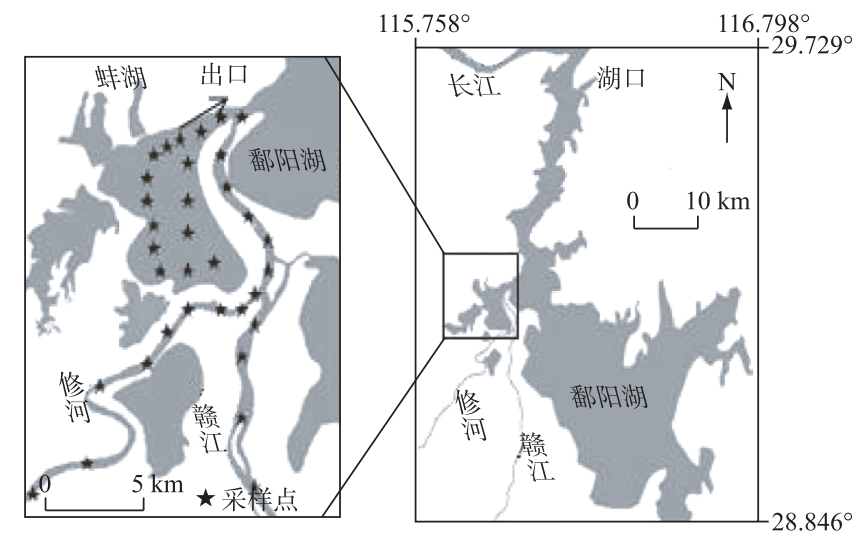

图 1 蚌湖及其周边水域采样点

Fig. 1 Sampling sites in Lake Bang and the surrounding waters

样品采集:2012 年 6 月于水深 $5 \mathrm{~m}$ 左右和 7 月于水深 $6 \mathrm{~m}$ 左右的丰水期在蚌湖采集水样、表层沉积物 和水生植物 (浮叶植物: 荇菜), 同时采集周边河流——赣江和修河的人湖口处的水样, 各样品的采集数量为 10 20 个, 其中湖泊中乘船在同地点采集水样、表层沉积物和水生植物, 采样量各 20 个左右; 周边河流乘船 采集水样量各 10 个. 沿河还进行了岸边土壤、陆地植物、农业废水、养殖废水、雨水和城市污水等的采集, 采 样量 2 5 个, 其中湿地采样是在枯水期 4 月进行. GPS 定位, 水样用 $5 \mathrm{~L}$ 有机玻璃采水器采集表层 $0.5 \mathrm{~m}$ 处 的湖水, 密封保存于干净聚乙烯瓶中, 其中 $500 \mathrm{ml}$ 水样现场加人浓 $\mathrm{H}_{2} \mathrm{SO}_{4}$ 使 $\mathrm{pH}<2$, 供实验室分析总氮 $(\mathrm{TN})$ 、总磷 $(\mathrm{TP})$ 、铵态氮 $\left(\mathrm{NH}_{4}^{+}-\mathrm{N}\right)$ 、硝态氮 $\left(\mathrm{NO}_{3}^{-}-\mathrm{N}\right)$ 和化学需氧量 $\left(\mathrm{COD}_{\mathrm{Cr}}\right) . \mathrm{HCO}_{3}^{-}$现场滴定. $1.5 \mathrm{~L}$ 水样用 $0.7 \mu \mathrm{m}$ Waterman 玻璃纤维滤膜 (预先灼烧, 去除氮) 过滤, 留在滤膜上的悬浮物 (浓度用重量法) 用于 $\mathrm{C} 、 \mathrm{~N}$ 含量、 $\mathrm{C} / \mathrm{N}$ 比和同位素分析, 水样用于无机氮同位素分析. 表层沉积物和土壤样品利用自制采样器采集 $0 \sim 5$ $\mathrm{cm}$ 的样品, 周边 3 次采样合并为 1 个样品, 存放于聚乙烯自封袋中, 于实验室冷冻干燥并磨碎过 100 目篮, 供 $\mathrm{C} 、 \mathrm{~N}$ 含量、 $\mathrm{C} / \mathrm{N}$ 比和同位素分析. 陆地植物和水生植物样品经数次纯水洗涤去除泥沙和藻类, 冷冻干燥并 磨碎过 100 目篮, 供 $\mathrm{C} 、 \mathrm{~N}$ 含量、C/N 比和同位素分析.

\section{2 样品分析}

水体理化分析: 水温、 $\mathrm{pH} 、 \mathrm{DO} 、 \mathrm{Eh}$ 和叶绿素 $\mathrm{a}$ ( Chl.a) 等由 HACH 水质参数分析仪和叶绿素仪现场测定. $\mathrm{TN} 、 \mathrm{TP} 、 \mathrm{NH}_{4}^{+}-\mathrm{N} 、 \mathrm{NO}_{3}^{-}-\mathrm{N} 、 \mathrm{HCO}_{3}^{-}$和 $\mathrm{COD}_{\mathrm{Cr}}$ 浓度, 分别采用过硫酸钾氧化紫外分光光度法、过硫酸钾氧化锄锑抗 分光光度法、纳氏试剂分光光度法、酚二磺酸分光光度法、酸碱指示剂滴定法和重铬酸钾氧化滴定法进行 测定 ${ }^{[22]}$.

同位素分析: 水样无机氮同位素 $\delta^{15} \mathrm{NH}_{4}^{+} 、 \delta^{15} \mathrm{NO}_{3}^{-}$分析之前进行预处理, 取过滤好的 $1.5 \mathrm{~L}$ 水样通过阴阳 离子交换树脂 Dowex1-x8、Dowex50w-x8 分别富集 $\mathrm{NO}_{3}^{-} 、 \mathrm{NH}_{4}^{+}$, 之后用 $2 \mathrm{~mol} / \mathrm{L} \mathrm{KCl}$ 洗脱再扩散, $\mathrm{NO}_{3}^{-}$的洗脱液 中加人定氮合金 ${ }^{[23]}$, 最后干燥成粉末供连续流同位素质谱仪分析 (CF-IRMS, Euro3000, Isoprine), 以标定硫 酸铵和 IAEA 硫酸铵分别为工作标准和国际标准, 分析误差为 $\pm 0.3 \%$. 固体样品有机碳处理: 加人 $0.5 \mathrm{~mol} / \mathrm{L}$ 的 $\mathrm{HCl}$ 酸化以去除无机碳, 淋洗至中性, 冷冻干燥. 有机 $\mathrm{C} 、 \mathrm{~N}$ 含量和 $\mathrm{C} / \mathrm{N}$ 比分析使用元素分析仪 (VarioMacro, German). 有机 $\mathrm{C} 、 \mathrm{~N}$ 同位素分析采用石英管灼烧法, 加人 $\mathrm{CuO}$ 丝, $\mathrm{N}$ 分析还需加人线状精 $\mathrm{Cu}$ 丝, 在真空 系统中抽真空后焊封, 于马弗炉 $850^{\circ} \mathrm{C}$ 灼烧 $5 \mathrm{~h}$, 然后纯化 $\mathrm{CO}_{2}$ 或 $\mathrm{N}_{2} . \mathrm{N}$ 同位素以 IAEA 硝酸钾为国际标准, 分析误差为 $\pm 0.2 \%$; C 同位素以美国南卡罗莱纳州白严系 Pee Dee 组拟箭石化石 (简称 PDB) 作为标准品, 分 析误差为 $\pm 0.2 \%$.

$$
\delta^{15} \mathrm{~N}\left(\text { 或 } \delta^{13} \mathrm{C}\right)=1000 \% 0\left(R_{\text {样品 }} / R_{\text {标准 }}-1\right)
$$

式中, $R$ 为 ${ }^{15} \mathrm{~N} /{ }^{14} \mathrm{~N}\left(\right.$ 或 $\left.{ }^{13} \mathrm{C} /{ }^{12} \mathrm{C}\right)$ 自然丰度比.

运用 SPSS 19.0 和 Sigmaplot 12.0 软件进行数据统计分析和作图. 


\section{2 结果与讨论}

\section{1 蛙湖及相邻水域水质特征}

鄱阳湖流域汛期是 5-8 月,蚌湖在 6 月和 7 月水深分别为 $5 \pm 0.3$ 和 $6 \pm 0.3 \mathrm{~m}$, 是丰水期, 水位的差异主 要是因为 7 月比 6 月更多的大到暴雨以及 7 月长江汛期对鄱阳湖水位的顶托作用. 湖水溶解氧浓度、弱碱 性. 7 月与 6 月相比, 样品的化学参数有较大增加, $\mathrm{NH}_{4}^{+}-\mathrm{N}$ 浓度增加了 0.3 倍, $\mathrm{TN} 、 \mathrm{HCO}_{3}^{-}$和 $\mathrm{COD}_{\mathrm{Cr}}$ 浓度均增加 了 1 倍 (表 1), $\mathrm{NO}_{3}^{-}-\mathrm{N}$ 浓度几乎增加了 2 倍, 反映了湖水有机质和无机氮的输人增加. 蚌湖 Chl. a 浓度不高, 说明藻类含量不高. $\mathrm{TP}$ 浓度变化范围为 $0.04 \sim 0.12 \mathrm{mg} / \mathrm{L}$. 以 $\mathrm{COD}_{\mathrm{Gr}} \mathrm{TN} 、 \mathrm{TP}$ 和 $\mathrm{NH}_{4}^{+}-\mathrm{N}$ 作为评价因子, 按照模 糊综合评价法的计算过程 ${ }^{[24]}$, 蚌湖丰水期为 $\mathrm{IV}$ 类水质, 处于中度富营养状态. 蚌湖水质差的决定因素是 TN 浓度. 评价因子对蚌湖水质影响的程度依次为 $\mathrm{TN}>\mathrm{TP}>\mathrm{NH}_{4}^{+}-\mathrm{N}>\mathrm{COD}_{\mathrm{Cr}}^{[20]}$. 蚌湖在丰水期悬浮颗粒物含量高, 6 月和 7 月均值分别为 65.6 和 $78.3 \mathrm{mg} / \mathrm{L}$, 从湖水外观也可以看出水体较为混浊.

表 1 蚌湖水体理化参数

Tab.1 The physical and chemical parameters of water in Lake Bang

\begin{tabular}{cccccccccc}
\hline 采样时间 & $\mathrm{pH}$ & $\begin{array}{c}\mathrm{DO} / \\
(\mathrm{mg} / \mathrm{L})\end{array}$ & \begin{tabular}{c}
$\mathrm{Chl. \textrm {a }}(\mu \mathrm{g} / \mathrm{L})$ \\
\hline 6月
\end{tabular} & $\begin{array}{l}\mathrm{HCO}_{3}^{-} / \\
(\mathrm{mg} / \mathrm{L})\end{array}$ & $\begin{array}{l}\mathrm{COD}_{\mathrm{Cr}} / \\
(\mathrm{mg} / \mathrm{L})\end{array}$ & $\begin{array}{c}\mathrm{NH}_{4}^{+}-\mathrm{N} / \\
(\mathrm{mg} / \mathrm{L})\end{array}$ & $\begin{array}{c}\mathrm{NO}_{3}^{-}-\mathrm{N} / \\
(\mu \mathrm{g} / \mathrm{L})\end{array}$ & $\begin{array}{c}\mathrm{TN} / \\
(\mathrm{mg} / \mathrm{L})\end{array}$ & $\begin{array}{c}\mathrm{TP} / \\
(\mathrm{mg} / \mathrm{L})\end{array}$ \\
\hline 7月 & $7.8 \pm 0.5$ & $8.5 \pm 1.7$ & $0.8 \pm 0.3$ & $44.7 \pm 12.3$ & $11.9 \pm 3.2$ & $0.24 \pm 0.04$ & $0.15 \pm 0.04$ & $1.8 \pm 0.6$ & $0.11 \pm 0.02$ \\
\end{tabular}

\section{2 蚌湖有机质碳、氮稳定同位素特征及其来源}

在水环境中, 有机 $\delta^{13} \mathrm{C} 、 \delta^{15} \mathrm{~N}$ 结合 $\mathrm{C} / \mathrm{N}$ 比可以有效地示踪有机质的来源, 不同来源的碳氮同位素有各自 的相对范围 ${ }^{[25-26]}$. C 3 植物的有机 $\delta^{13} \mathrm{C}$ 为 $-32 \% 0 \sim-24 \%, \delta^{15} \mathrm{~N}$ 值为 $3 \% 0 \sim 7 \%$; 土壤有机质 $\delta^{13} \mathrm{C}$ 为 $-25 \%$ $-22 \%, \delta^{15} \mathrm{~N}$ 值为 $0 \sim 5 \%$; $\mathrm{C} 4$ 植物 $\delta^{13} \mathrm{C}$ 为 $-17 \% 0 \sim-9 \%$; 水体中水生植物 $\delta^{13} \mathrm{C}$ 为 $-31 \% 0 \sim-26 \%, \delta^{15} \mathrm{~N}$ 值为 $6 \% \sim 11 \%$; 藻类的 $\delta^{13} \mathrm{C}$ 偏负, 为 $-42 \% 0 \sim-24 \%$, 均值为 $-30 \%$. 陆源植物 $\mathrm{C} / \mathrm{N}$ 比通常为 $15 \sim 30$, 藻类的降解 产物含有较多的蛋白质, 其 $\mathrm{C} / \mathrm{N}$ 比一般小于 7 , 水生植物 $\mathrm{C} / \mathrm{N}$ 比介于陆源植物与藻类之间, 为 $10 \sim 20$, 土壤 有机质 $\mathrm{C} / \mathrm{N}$ 比为 $8 \sim 15$, 同时有机质的降解也将改变 $\mathrm{C} / \mathrm{N}$ 比 ${ }^{[6,27]}$.

蛙湖周边陆地 $\mathrm{C} 3$ 植物的 $\delta^{13} \mathrm{C}$ 较负, 均值小于 $-27.9 \%, \delta^{15} \mathrm{~N}$ 均值大于 $7 \%{ }^{[28]}, \mathrm{C} 4$ 植物的 $\delta^{13} \mathrm{C}$ 均值为 $-17.4 \% 0 \pm 1.0 \%$; 土壤有机质 $\delta^{13} \mathrm{C}$ 比 C3 植物偏正, 均值大于 $-25.2 \% 0, \delta^{15} \mathrm{~N}$ 最低, 均值范围为 $3.2 \% 0 \sim 3.7 \% 0$; 沉 积物的 $\delta^{13} \mathrm{C}$ 值介于 $\mathrm{C} 3$ 植物和土壤有机质之间, $\delta^{15} \mathrm{~N}$ 范围为 $5 \%$ \% 7\%. 陆地植物的 $\mathrm{C} / \mathrm{N}$ 比最大, 大于 17 , 土 壤有机质的 $\mathrm{C} / \mathrm{N}$ 比均值大于 12 (蚌湖堤坝土壤 $\mathrm{C} / \mathrm{N}$ 比小于 10 , 实际上在丰水期被水淹), 沉积物的 $\mathrm{C} / \mathrm{N}$ 比 均值在 10 左右 (表 2). 这些不同来源的 $\delta^{13} \mathrm{C} 、 \delta^{15} \mathrm{~N}$ 及 $\mathrm{C} / \mathrm{N}$ 比差异较大,较好区分.

表 2 蚌湖和周边河流有机质碳、氮稳定同位素特征值

Tab.2 Carbon and nitrogen stable isotopes of organic matter in Lake Bang and the surrounding rivers

\begin{tabular}{cccccc}
\hline 来源 & 类型 & $\delta^{13} \mathrm{C}(\mathrm{TOC}) / \% 0$ & $\delta^{15} \mathrm{~N}(\mathrm{TN}) / \% 0$ & $\mathrm{C} / \mathrm{N}$ 比 & 数量 \\
\hline 蚌湖湿地 & 植物 & $-25.9 \pm 0.9$ & $7.9 \pm 0.6$ & $15.9 \pm 1.8$ & 3 \\
蚌湖岸边 & $\mathrm{C} 3$ 植物 & $-27.9 \pm 0.5$ & $7.8 \pm 0.8$ & $20.9 \pm 4.3$ & 4 \\
蚌湖岸边 & $\mathrm{C} 4$ 植物 & $-17.4 \pm 1.0$ & $6.5 \pm 0.9$ & $17.9 \pm 4.9$ & 5 \\
赣江岸边 & 植物 & $-28.7 \pm 0.6$ & $7.4 \pm 3.0$ & $26.6 \pm 7.9$ & 2 \\
修河岸边 & 植物 & $-29.3 \pm 0.2$ & $9.4 \pm 0.9$ & $20.7 \pm 0.2$ & 2 \\
赣江岸边 & 土壤 & $-25.0 \pm 0.2$ & $3.2 \pm 0.4$ & $17.4 \pm 0.8$ & 3 \\
修河岸边 & 土壤 & $-25.2 \pm 0.5$ & $3.8 \pm 0.4$ & $12.6 \pm 0.7$ & 3 \\
蚌湖堤坝 & 土壤 & $-23.6 \pm 0.3$ & $3.5 \pm 0.3$ & $8.6 \pm 0.6$ & 3 \\
赣江湿地 & 沉积物 & $-26.2 \pm 0.4$ & $6.8 \pm 0.6$ & $11.0 \pm 1.1$ & 3 \\
修河湿地 & 沉积物 & $-24.1 \pm 2.0$ & $6.4 \pm 0.7$ & $9.8 \pm 0.1$ & 3 \\
蚌湖湿地 & 沉积物 & $-26.7 \pm 1.5$ & $6.4 \pm 0.9$ & $9.5 \pm 0.8$ & 3 \\
\hline
\end{tabular}


2.2.1 水生植物同位素特征 水生植物 $\delta^{13} \mathrm{C}$ 在 6 月范围为 $-28.8 \% 0 \sim-24.9 \%$, 均值为 $-26.8 \% 0 \pm 1.3 \% 0,7$ 月范 围为 $-29.3 \% 0 \sim-23.2 \% 0$, 均值为 $-26.0 \% 0 \pm 1.8 \%$ ( 图 2a). 采集的水生植物是浮叶植物, 6 月和 7 月是夏季, 有 较高的温度和强烈的光照, $\delta^{13} \mathrm{C}$ 主要影响因素是光合作用和呼吸作用, 与水体的无机碳含量关系不大, 故 $\delta^{13} \mathrm{C}$ 差别较小. $\delta^{15} \mathrm{~N}$ 在 6 月范围为 $5.3 \% 0 \sim 8.2 \%$, 均值为 $6.6 \% 0 \pm 1.1 \% 0,7$ 月范围为 $7.4 \% 0 \sim 11.0 \%$, 均值为 $8.8 \% 0 \pm 1.1 \%$, 比 6 月偏正 $2.2 \%$. 水生植物氮的主要来源是叶片和根系从水体和底泥中吸收无机氮, 无机氮 $\delta^{15} \mathrm{~N}$ 的变化会使有机质的 $\delta^{15} \mathrm{~N}$ 值存在明显差异, 水生植物的 $\delta^{15} \mathrm{~N}$ 可以作为人为氮输人影响的指标 ${ }^{[29]} .7$ 月 水生植物 $\delta^{15} \mathrm{~N}$ 的明显升高说明吸收了 $\delta^{15} \mathrm{~N}$ 值更高的无机氮, 比如废水无机氮. $\mathrm{C} / \mathrm{N}$ 比在 6 月为 $9.9 \sim 16.7$, 均值为 $13.5 \pm 1.3 ; 7$ 月为 $8.8 \sim 14.9$, 均值为 $12.6 \pm 1.5$, 比 6 月略有降低.

2.2 .2 表层沉积物同位素特征 蚌湖表层沉积物 $\delta^{13} \mathrm{C}$ 在 6 月范围为 $-26.5 \% 0 \sim-24.4 \% 0$, 均值为 $-25.3 \% 0 \pm$ $0.8 \% 0 ; 7$ 月范围为 $-25.7 \% 0 \sim-24.3 \%$, 均值为 $-24.8 \% 0 \pm 0.5 \%$, 比 6 月略偏正 (图 $2 \mathrm{~b}$ ). $\delta^{15} \mathrm{~N}$ 在 6 月范围为 $5.2 \% 0 \sim 6.2 \%$, 均值为 $5.6 \% 0 \pm 0.3 \%$; 7 月范围为 $5.7 \% 0 \sim 6.8 \%$, 均值为 $6.3 \% 0 \pm 0.3 \%$, 比 6 月偏正 $0.7 \%$. C/ $\mathrm{N}$ 比 在 6 月为 $6.2 \sim 9.1$, 均值为 $7.9 \pm 1.0 ; 7$ 月为 7.3 10.3, 均值为 $8.4 \pm 1.1$, 比 6 月略偏高, 整体来说沉积物的 $\delta^{13} \mathrm{C}$ 、 $\delta^{15} \mathrm{~N}$ 和 $\mathrm{C} / \mathrm{N}$ 比在 7 月比 6 月略偏高. 沉积物的 $\delta^{13} \mathrm{C}$ 落在水生植物和土壤有机质的 $\delta^{13} \mathrm{C}$ 之间 (表 2 , 图 $2 \mathrm{a}$ ), 与藻类的 $\delta^{13} \mathrm{C}(-30 \% 0)$ 相差较大; 沉积物的 $\delta^{15} \mathrm{~N}$ 比土壤有机质的偏高 $2.5 \% 0 \sim 3.2 \%$, 而比水生植物的偏低 $1 \% 0 \sim 2.5 \%$; 沉积物的 $\mathrm{C} / \mathrm{N}$ 比水生植物和土壤有机质的都低于 4 以上, 但是沉积物的 $\mathrm{C} / \mathrm{N}$ 比都大于 7(一般 藻类小于 7). 沉积物在成岩过程中伴随着矿化降解, 矿化作用的同位素分馏较小 ${ }^{[30]}$, 但矿化降解降低了 $\mathrm{C} / \mathrm{N}$ 比值 ${ }^{[11]}$. 藻类对表层沉积物的贡献较弱.
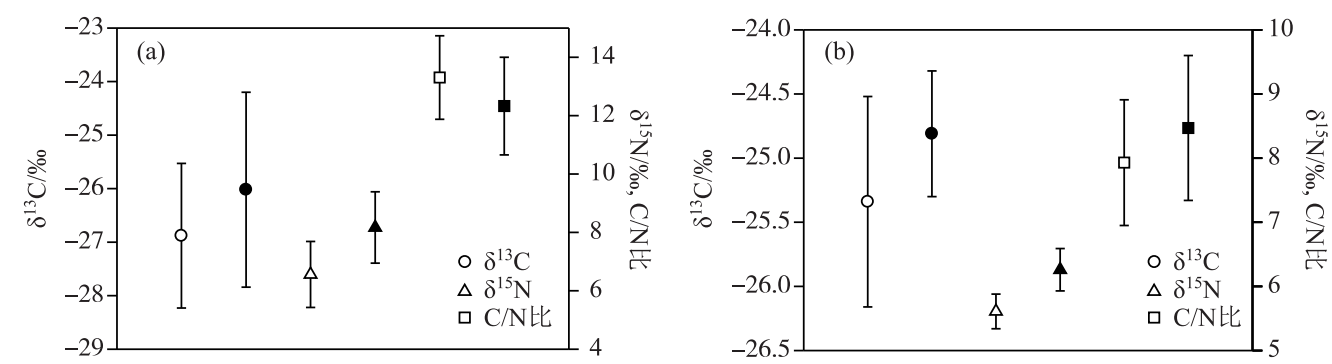

图 2 水生植物 ( a ) 和表层沉积物 (b) 的 $\delta^{13} \mathrm{C} 、 \delta^{15} \mathrm{~N}$ 和 $\mathrm{C} / \mathrm{N}$ 比分布 (白色和黑色图例分别表示 6 月和 7 月样品)

Fig.2 Distributions of $\delta^{13} \mathrm{C}, \delta^{15} \mathrm{~N}$ and $\mathrm{C} / \mathrm{N}$ of aquatic plant (a) and surface sediment (b)

2.2.3 蚌湖悬浮颗粒物、表层沉积物和水生植物的关系 蚌湖的悬浮颗粒物、表层沉积物和水生植物的 $\delta^{13} \mathrm{C}$ 差别不大 (图 3), 悬浮颗粒物的 $\delta^{15} \mathrm{~N}\left(4 \% 0 \sim 6 \%\right.$ ) 比表层沉积物和水生植物的 $\delta^{15} \mathrm{~N}$ 都低, 归因于土壤有机质 参与其组成 (表 2), 悬浮颗粒物比沉积物的 $\mathrm{C} / \mathrm{N}$ 比稍高, 但比水生植物低较多, 可能是因为悬浮颗粒物往往 是由降解的碎屑组成.

蚌湖丰水期水深有 $4.8 \sim 6.5 \mathrm{~m}$, 风浪的作用使表层沉积物悬浮作用不大, 所以悬浮物的组成中沉积物的 悬浮较小, 沉积物的组成则是悬浮颗粒物携带的土壤有机质和水生植物经过矿化改造的混合沉降.

2.2.4 蚌湖及周边河流中悬浮颗粒物的同位素特征及其来源 悬浮颗粒物在蚌湖 6 月的 $\delta^{13} \mathrm{C}$ 范围为 $-26.7 \% 0 \sim-23.7 \%$, 平均值为 $-25.1 \% 0 \pm 1.2 \%$ （图 4), 7 月 $\delta^{13} \mathrm{C}$ 范围为 $-27.6 \% 0 \sim-23.2 \%$, 均值为 $-25.5 \% 0 \pm$ $1.3 \%$, 比 6 月略偏负; 贑江 6 月的 $\delta^{13} \mathrm{C}$ 范围为 $-26.3 \%$ $-24.3 \%$, 均值为 $-25.3 \% 0 \pm 0.4 \%$, 7 月范围为 $-26.8 \% 0 \sim$ $-24.8 \%$, 均值为 $-25.9 \% \pm 0.7 \%$, 比 6 月略偏负, 赣江与蚌湖的 $\delta^{13} \mathrm{C}$ 差别不大; 修河 6 月的 $\delta^{13} \mathrm{C}$ 范围为 $-27.23 \% 0 \sim-25.72 \%$, 均值为 $-26.32 \% 0 \pm 0.35 \%$, 7 月范围为 $-27.47 \% 0 \sim-26.31 \% 0$, 均值为 $-26.82 \% 0 \pm 0.51 \%$, 比 6 月略偏负, 修河比赣江和蚌湖的 $\delta^{13} \mathrm{C}$ 均偏负 $0.8 \% \sim 1.7 \%$, 可能有更多的陆地植物碎屑进入修河. 蚌湖悬 浮颗粒物 $\delta^{13} \mathrm{C}$ 值均介于土壤有机质和水生植物碎屑之间, 比陆地植物偏正 (大约 $3 \%$ ), 表明其来源主要是 土壤有机质和水生植物的混合 (表 2). 赣江和修河的悬浮颗粒物 $\delta^{13} \mathrm{C}$ 介于土壤有机质和陆地植物的 $\delta^{13} \mathrm{C}$ 之间. $\delta^{13} \mathrm{C}$ 在 7 月比 6 月偏负, 表明 7 月有更多的陆源物质输人.

悬浮颗粒物在蚌湖 6 月 $\delta^{15} \mathrm{~N}$ 的范围为 $2.6 \% 0 \sim 6.2 \%$, 均值为 $4.1 \% 0 \pm 1.2 \%$, 7 月的范围为 $4.3 \% 0 \sim 7.7 \%$, 

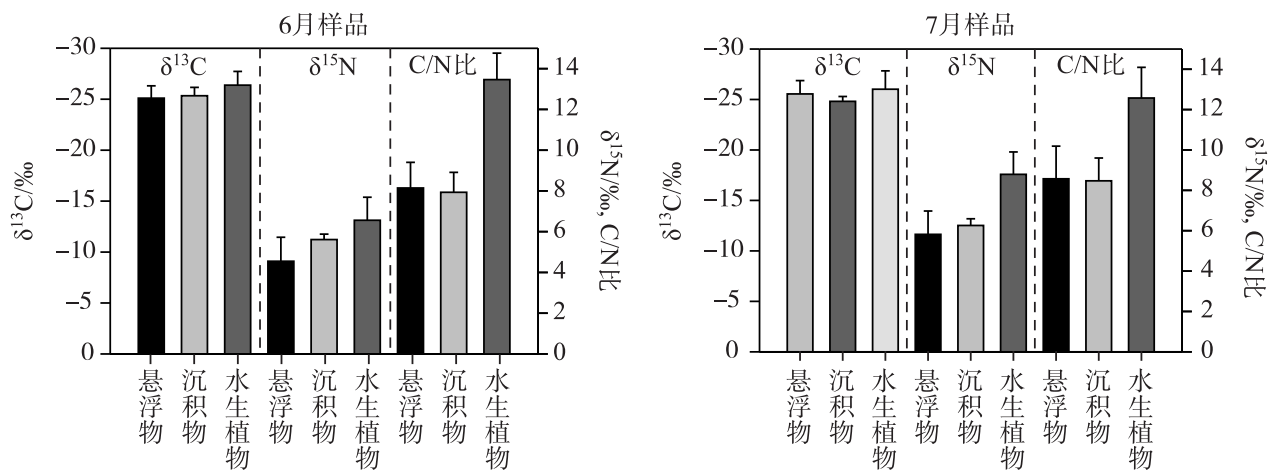

图 3 悬浮物与表层沉积物、水生植物的碳氮同位素关系

Fig. 3 The relations of suspend particle matter and the carbon and nitrogen stable isotopes of surface sediment and aquatic plant

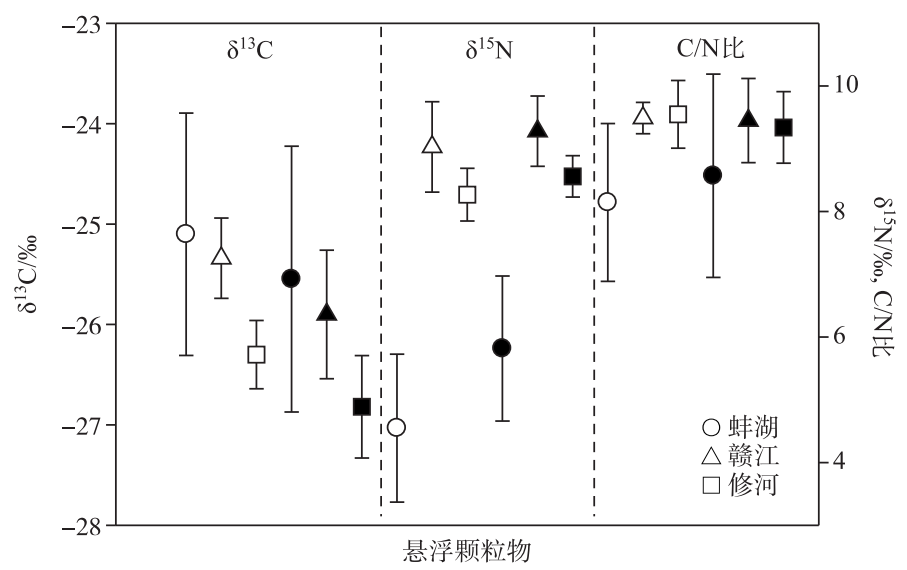

图 4 蚌湖及周边河流悬浮颗粒物的 $\delta^{13} \mathrm{C} 、 \delta^{15} \mathrm{~N}$ 和 $\mathrm{C} / \mathrm{N}$ 比分布 (白色和黑色图例分别表示 6 月和 7 月样品)

Fig.4 Distributions of $\delta^{13} \mathrm{C}, \delta^{15} \mathrm{~N}$ and $\mathrm{C} / \mathrm{N}$ of suspend particle matter in Lake Bang and the surrounding rivers

均值为 $5.8 \% 0 \pm 1.2 \% 0,7$ 月比 6 月偏正 $1.7 \%$, 但均值都小于 7\% , 大于 $3.5 \%$, 表现为土壤有机质和水生植物的 混合特征 (表 2, 图 2a); 赣江 6 月的范围为 $5.34 \%$ 10.32\%o, 均值为 $9.03 \%{ }_{0} \pm 0.72 \%$, 7 月为 $9.3 \% \pm 0.6 \%$, 比 6 月略偏正, 赣江悬浮颗粒物的 $\delta^{15} \mathrm{~N}$ 比土壤有机质的高 $5 \%$ 以上, 也比陆地植物的 $\delta^{15} \mathrm{~N}$ 高 $(7.43 \% 0 \pm 3.01 \% 0$, 表 2 ), 结合 $\delta^{13} \mathrm{C}$, 表明赣江有更高 $\delta^{15} \mathrm{~N}$ 的废水有机质 ( 7\%0 25\%o ) 输人; 修河 6 月为 $8.3 \% 0 \pm 0.4 \% 0,7$ 月为 $8.5 \% 0 \pm$ $0.3 \%$, 比 6 月略偏正, 修河的 $\delta^{15} \mathrm{~N}$ 比土壤有机质 (3.79\% $0.37 \% 0$ ) 高较多, 比陆地植物 ( $9.39 \% 0 \pm 0.95 \% 0$ ) 略低 (表 2), 表明修河的悬浮颗粒有机质中陆地植物碎屑的贡献较大, 不能排除废水有机质输人的可能. 赣江和 修河的 $\delta^{15} \mathrm{~N}$ 比蚌湖高 4\%o 5\% , 表明蚌湖的悬浮颗粒有机质的来源不仅有河流的运输, 更多地来自于土壤 有机质和水生植物的混合, 因为丰水期大到暴雨冲刷陆地带来周边更多的土壤有机质输人蚌湖. 蚌湖与河 流的悬浮颗粒有机质 $\delta^{15} \mathrm{~N}$ 的较大差别, 从另一方面反映蚌湖与河流的水交换在丰水期不彻底, 蚌湖水源主 要是滞留的河水与湖面降雨的混合, 后面无机氮的来源也将说明这一点.

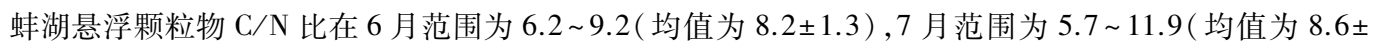
1.6) ; 赣江的悬浮颗粒物 $\mathrm{C} / \mathrm{N}$ 比在 6 月为 $9.5 \pm 0.3,7$ 月为 $9.5 \pm 0.7$; 修河的悬浮颗粒物 $\mathrm{C} / \mathrm{N}$ 比在 6 月为 $9.5 \pm$ $0.5,7$ 月为 $9.3 \pm 0.6$. 湖泊和河流的悬浮颗粒物的 $\mathrm{C} / \mathrm{N}$ 比低于水生植物和土壤有机质的 $\mathrm{C} / \mathrm{N}$ 比 (均值 $>12$ ) (图 1, 图 3, 表 2), 一方面是由于悬浮颗粒物组成往往是衰败的植物碎屑, 在夏季水环境中较强的矿化、生 物降解作用降低了 $\mathrm{C} / \mathrm{N}$ 比. 另一方面不能排除大雨冲刷陆地带来的低 $\mathrm{C} / \mathrm{N}$ 比的废水有机质输人的可能 (如 
城镇污物、动物粪肥的 $\mathrm{C} / \mathrm{N}$ 比范围 $6 \sim 13^{[3]}$ ).

悬浮颗粒物的 $\delta^{13} \mathrm{C} 、 \delta^{15} \mathrm{~N}$ 结合 $\mathrm{C} / \mathrm{N}$ 比示踪湖泊和河流的有机质的来源, 表明蚌湖的悬浮颗粒物主要来 源于土壤有机质和水生植物的混合. 赣江和修河的悬浮颗粒物主要来源于土壤有机质和陆地植物碎屑, 并 且废水有机质有一定贡献. 藻类对湖泊和河流悬浮颗粒有机质的贡献较小.

\section{3 无机氮同位素特征及转化过程}

不同来源的无机氮组成有不同的 $\delta^{15} \mathrm{~N}$ 特征值, 合成化肥大约为 $0 \pm 2 \%{ }^{[31]}$, 其中 $\mathrm{NO}_{3}^{-}$肥的 $\delta^{15} \mathrm{~N}$ 值一般 在 $-2.5 \%$ 2.0\% 之间, $\mathrm{NH}_{4}^{+}$肥的 $\delta^{15} \mathrm{~N}$ 值一般在 $-4 \% 0 \sim 2 \%$ 之间; 动物废水 $\delta^{15} \mathrm{~N}$ 范围为 $8 \% 0 \sim 20 \%{ }^{[32]}$, 雨水中 $\mathrm{NH}_{4}^{+}$的 $\delta^{15} \mathrm{~N}$ 范围为 $-30 \% 0 \sim 0, \mathrm{NO}_{3}^{-}$的 $\delta^{15} \mathrm{~N}$ 范围为 $-10 \% 0 \sim 2 \%{ }^{[33]}$. 无机氮同位素被广泛应用于水环境中氮的 来源与转化研究 ${ }^{[34-37]}$. 我国不同地区地表水、地下水和雨水的无机氮 $\delta^{15} \mathrm{~N}$ 现有数据不同, 对于研究区域水 体中氮的来源和氮循环转化具有重要的意义 ${ }^{[8,38-39]}$.

本研究中雨水、养鱼废水、养猪废水和城镇生活废水中无机氮都是以铵态氮为主, 只有农田、蔬菜地以 硝态氮为主 (图 5a). 雨水中的铵态氮同位素值最负 $(-13.5 \% 0 \pm 5.9 \%$ ) (图 $5 \mathrm{~b}$ ), 养鱼和养猪废水和城镇废水 的铵态氮同位素值较正 (大于 $12 \% 0$ ), 而硝态氮同位素以养鱼废水为最负 $(-7.2 \% 0 \pm 2.2 \% 0$ ), 养猪废水为最正 $(7.0 \% 0 \pm 2.3 \% 0)$, 这些氮同位素值差异较大, 容易区分. 雨水、城镇废水、农业蔬菜地和化肥的硝态氮同位素 值差别不大. 农业蔬菜地和稻田废水的铵态氮同位素值也表现为化肥的氮同位素值, 表明农业种植地的氮 来源以化肥为主.
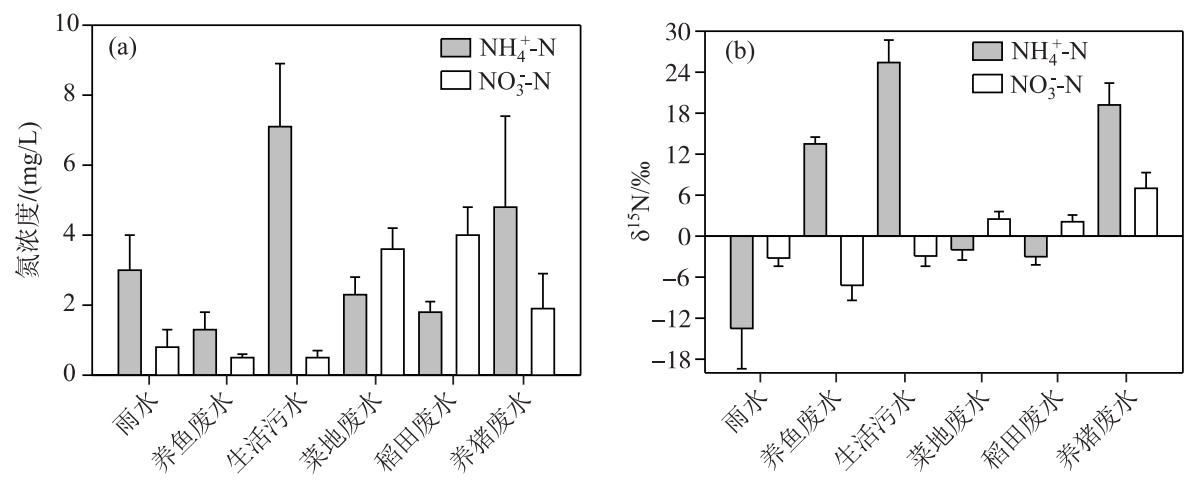

图 5 沿河流域废水中铵态氮和硝态氮浓度 (a) 以及同位素特征值 $(b)$

Fig.5 Concentrations (a) and isotopes (b) of ammonia- $\mathrm{N}$ and nitrate- $\mathrm{N}$ of waste water along rivers

蚌湖从 6-7 月无机氮主要形式从铵态氮转变 为硝酸盐氮, 表明暴雨的冲涮带来了更多面源污染 的农业化肥输人, 实际上此时也是农田第二季水稻 种植的时期.

蚌湖的 $\delta^{15} \mathrm{NH}_{4}^{+}$在 6 月最负 $(-18.6 \% 0 \pm 5.2 \% 0)$, 表现为雨水铵态氮同位素特征, 以雨水输人为主, 在 7 月则显著升高 $(-12.2 \% 0 \pm 3.2 \%$ ) , 增加了 $6 \%$ ( 图 6). 蚌湖的相邻水域贑江和修河在 6 月的 $\delta^{15} \mathrm{NH}_{4}^{+}$也 为负值 (分别为 $-8.9 \% 0 \pm 1.8 \% 0$ 和 $-11.8 \% \pm 1.6 \%$ ), 表 现为以雨水输人为主, 在 7 月也升高了 $2.6 \%$ 和 $1.3 \% 0$ ( 分别为 $-5.4 \% 0 \pm 1.64 \% 0$ 和 $-10.5 \% 0 \pm 1.4 \% 0$ ). 蚌 湖的 $\delta^{15} \mathrm{NH}_{4}^{+}$比赣江和修河的均值偏负 7\%o 10\%o, 蚌湖的湖面降雨量更明显, 也表明蚌湖与河流的水 量交换不彻底,蚌湖水源可能主要为滞留的河水和

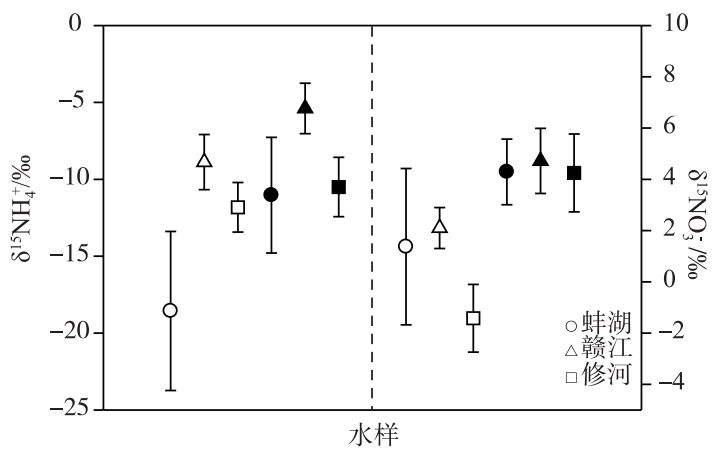

图 6 蚌湖及周边河流 $\delta^{15} \mathrm{NH}_{4}^{+}$和 $\delta^{15} \mathrm{NO}_{3}^{-}$分布特征 (白色和黑色图例分别表示 6 月和 7 月水样)

Fig. 6 Distribution of $\delta^{15} \mathrm{NH}_{4}^{+}$and $\delta^{15} \mathrm{NO}_{3}^{-}$in

Lake Bang and the surrounding rivers 
湖面降雨.

蚌湖的 $\delta^{15} \mathrm{NO}_{3}^{-}$在 6 月变化范围较宽, 为 $-5.5 \% 0 \sim 5.8 \%$, 均值 $1.4 \% 0 \pm 3.0 \%$, 表现为雨水和农业化肥混合 输人特征; 7 月范围为 $-1.7 \% 0 \sim 5.9 \%$, 均值升高到 $4.3 \% 0 \pm 1.3 \%$, 表现为农业化肥输人为主, 可能还有高同位 素值的废水输人. 赣江和修河的 $\delta^{15} \mathrm{NO}_{3}^{-}$在 6 月分别为 $2.2 \%{ }_{0} \pm 0.8 \%$ 和 $-1.4 \%{ }_{0} \pm 1.3 \%$, 表现为农业化肥和雨水 输人特征, 7 月有明显的升高, 分别为 $4.7 \% \pm 1.3 \% 0$ 和 $4.2 \% \pm 1.6 \%$, 表现为农业化肥输人为主, 可能还有高同 位素值的废水输人.

无机氮在水体迁移转化过程中发生的硝化作用、反硝化作用和同化作用等过程会引起氮同位素分 馏 ${ }^{[13,40]}$. 硝化作用使剩余的 $\delta^{15} \mathrm{NH}_{4}^{+}$升高, $\mathrm{NH}_{4}^{+}-\mathrm{N}$ 浓度降低, 且 $\delta^{15} \mathrm{NO}_{3}^{-}$降低 (轻同位素首先参与转化); 反硝化 作用使 $\delta^{15} \mathrm{NO}_{3}^{-}$升高, 而 $\mathrm{NO}_{3}^{-}-\mathrm{N}$ 浓度降低, 这些浓度与同位素的关系常用来示踪水体氮的转化过程 ${ }^{[41]}$, 或判 别来自动物粪便或污水的氮污染 ${ }^{[42]}$, 比如 Mariotti 等 ${ }^{[43]}$ 示踪地下水氮的稀释作用在 $\delta^{15} \mathrm{NO}_{3}^{-}$与 $1 / \mathrm{NO}_{3}^{-}$关系图 上为一直线, 而反硝化作用在 $\delta^{15} \mathrm{NO}_{3}^{-}$与 $\ln \left[\mathrm{NO}_{3}^{-}\right]$关系图上为一直线. 吴庆乐等 ${ }^{[16]}$ 在太湖西部湖区分析氮污 染转化过程中发现, 无机氮浓度与同位素值存在相反关系, 认为发生了较为显著的硝化作用. 蚌湖从 6 月到 7 月 $\delta^{15} \mathrm{NH}_{4}^{+}$大幅增加了 $6 \%, \delta^{15} \mathrm{NO}_{3}^{-}$均值也增加 $3 \%, \mathrm{NH}_{4}^{+}-\mathrm{N}$ 和 $\mathrm{NO}_{3}^{-}-\mathrm{N}$ 浓度也分别增加了 0.3 和 2 倍, 统计结 果表明蚌湖的 $\delta^{15} \mathrm{NH}_{4}^{+}$与 $\delta^{15} \mathrm{NO}_{3}^{-}$不存在相反关系, 浓度与同位素值直线关系也弱 $\left(R^{2}=0.1124\right.$ 或 0.1949$)$. 蛙 湖是浅水湖泊,夏季温度高, 溶解氧丰富, 水体容易发生矿化作用和硝化作用, 不容易发生反硝化作用. 大幅 增加的无机氮同位素值和浓度表明蚌湖存在较高 $\delta^{15} \mathrm{~N}$ 的外源废水氮输人 (图 $5 \mathrm{a}, \mathrm{b}$ ). 在赣江近蚌湖 $100 \mathrm{~km}$ 处有南昌市大城市存在, 修河近蚌湖 $10 \mathrm{~km}$ 处有永修县县城分布, 而且鄱阳湖流域是农业河流, 前些年沿河 和蚌湖沿岸有不少分散的养猪养牛场分布. 丰水期经常性的暴雨冲刷陆地容易将畜禽粪肥输人水域, 严重 增加了水体的氮污染. 7 月采样的时间即是在暴雨过后的第 3 天. 丰水期蚌湖与鄱阳湖水位保持一致,同时 长江在 7 月也是汛期, 鄱阳湖水受长江来水的顶托作用不能下泄, 故蚌湖水流缓慢, 污染物容易蓄积在湖内.

从以上分析无机氮同位素值和浓度的变化可知, 丰水期蚌湖的无机氮主要来自于雨水和农业化肥, 暴 雨的冲涮会带来城镇生活废水和畜禽养殖废水的威胁.

\section{3 结论}

利用碳氮同位素结合碳氮比示踪丰水期蚌湖有机质氮和无机氮的来源, 蚌湖悬浮颗粒有机质以土壤有 机质和水生植物碎屑的混合为主. 水生植物是蚌湖重要的内源氮来源, 其 $\delta^{15} \mathrm{~N}$ 值主要受到无机氮 $\delta^{15} \mathrm{~N}$ 的影 响, 暴雨冲涮带来的高 $\delta^{15} \mathrm{~N}$ 废水明显提高了水生植物的 $\delta^{15} \mathrm{~N}$ 值. 藻类对有机质的贡献较弱. 蚌湖的无机氮 主要来源于雨水和农业化肥, 暴雨的冲涮作用也带来了城镇生活废水和畜禽养殖废水的威胁. 蚌湖和鄱阳 湖一样是洪泛湖泊, 本研究有利于对这种类型湖泊的营养输人和控制污染的管理提供科学依据, 更期望于 加强长江中下游洪泛类型湖泊的氮循环和迁移转化研究.

\section{4 参考文献}

[ 1 ] Camargo JA, Alonso A. Ecological and toxicological effects of inorganic nitrogen pollution in aquatic ecosystems: A global assessmen. Environment International, 2006, 32(6) : 831-849.

[ 2 ] Shan BQ, Jian YX, Tang WZ et al. Temporal and spatial variation of nitrogen and phosphorus and eutrophication assessment in downstream river network areas of North Canal River Watershed. Environmental Science, 2012, 33(2) : 352-358. [单保庆, 菅宇翔, 唐文忠等. 北运河下游典型河网区水体中氮磷分布与富营养化评价. 环境科学, 2012, 33(2): 352-358.]

[ 3 ] Guo QJ, Wang CY, Zhu GX et al. Research on the source and migration process of organic matter of lake sediments using nitrogen isotope-A case study in Beijing. Bulletin of Mineralogy, Petrology and Geochemistry, 2015, 34(3) : 532-538. [ 郭庆军, 王春雨, 朱光旭. 氮同位素研究城市湖泊沉积物有机质来源和迁移过程一一北京为例. 矿物岩石地球 化学通报, 2015, 34(3): 532-538.]

[ 4 ] Kelley CJ, Keller CK, Evans RD et al. Nitrate-nitrogen and oxygen isotope ratios for identification of nitrate sources and dominant nitrogen cycle processes in a tile-drained dryland agricultural field. Soil Biology and Biochemistry, 2013, 57 : $731-738$ 
[ 5 ] Hadas O, Altabet MA, Agnihotri R. Seasonally varying nitrogen isotope biogeochemistry of particulate organic matter in Lake Kinneret, Israel. Limnology and Oceanography, 2009, 54: 75-85.

[ 6 ] Kendall C, Silva SR, Kelly VJ. Carbon and nitrogen isotopic compositions of Particulate organic matter in four large river systems across the United States. Hydrology Process, 2001, 15: 1301-1346.

[ 7 ] Xiao HY, Liu CQ. Nitrogen isotope studies on seasonal nitrogen pollution of inflowing rivers of Hongfeng Lake, Guizhou Province. Earth and Environment, 2004, 32(1): 71-75. [肖化云, 刘丛强. 氮同位素示踪贵州红枫湖河流季节性氮 污染. 地球与环境, 2004, 32(1): 71-75.]

[ 8 ] Lin L, Wu JL, Zeng HA et al. Stable nitrogen isotope tracing anthropogenic influence on Lake Taihu. J Lake Sci, 2012, 24(4) : 546-552. DOI: 10.18307/2012.0407. [林琳, 吴敬禄, 曾海鳌等. 人类活动对太湖水环境影响的氮同位素示 踪. 湖泊科学, 2012, 24(4): 546-552.]

[ 9 ] Xiao HY, Liu CQ. Composition of nitrogen isotope in recent sediment of Hongfeng Lake indicating waste water condition, Guizhou. Chinese Science Bulletin, 2006, 51(9) : 1091-1096. [肖化云, 刘丛强. 贵州红枫湖现代沉积物氮同位素组 成反映的废水输人状况. 科学通报, 2006, 51(9): 1091-1096.]

[10] Besemer K, Luef B, Preiner S et al. Sources and composition of organic matter for bacterial growth in a large European river floodplain system (Danube, Austria). Org Geochem, 2009, 40: 321-331.

[11] Liu CQ, Lang YC, Li SL et al. Researches on biogeochemical processes and nutrient cycling in karstic ecological systems, southwest China: A review. Earth Science Frontiers, 2009, 16(6): 1-12. [刘丛强, 郎紊超, 李思亮等. 喀斯特生态系 统生物地球化学过程与物质循环研究: 重要性、现状与趋势. 地学前缘, 2009, 16(6): 1-12.]

[12] Xing M, Liu WG, Hu J. Using nitrate isotope to trace the nitrogen pollution in Chanhe and Laohe River. Environmental Science, 2010, 10(10) : 2305-2310. [邢萌, 刘卫国, 胡婧. 浐河、涝河河水硝酸盐氮污染来源的氮同位素示踪. 环 境科学, 2010, 10(10): 2305-2310.]

[13] Xue D, Botte J, Baets BD et al. Present limitations and future prospects of stable isotope methods for nitrate source identification in surface and groundwater. Water Research, 2009, 43: 1159-1170.

[14] Xing GX, Cao YC, Shi SL et al. N pollution sources and denitrification in waterbodies in Taihu Lake region. Science in China Series B: Chemistry, 2001, 44(3) : 304-314.

[15] Chen ZX, Yu L, Liu WG et al. Nitrogen and oxygen isotopic compositions of water-soluble nitrate in Taihu Lake water system, China: implication for nitrate sources and biogeochemical process. Environmental Earth Sciences, 2013, 71 (1): 217-223

[ 16] Wu QL, Ruan XH, Wu CM et al. Analyses of sources and transformation of nitrogen as a contaminant in the river and lake water in the western region of the Taihu Lake basin. Acta Scientiae Circumstantiae, 2015, 35(12) : 3883-3889. [吴庆乐, 阮晓红, 吴朝明等.太湖西部河湖氮污染物来源及转化途径分析. 环境科学学报, 2015, 35(12) : 3883-3889.]

[17] Wang ML, Lai JP, Hu KT et al. Compositions and sources of stable organic carbon and nitrogen isotopes in surface sediments of Poyang Lake. China Environmental Science, 2014, 34(4) : 1019-1025. [王毛兰, 赖建平, 胡珂图等. 鄱阳湖 表层沉积物有机碳、氮同位素特征及其来源分析. 中国环境科学, 2014, 34(4)：1019-1025.]

[18] Wang ML, Lai JP, Hu KT et al. Compositions of stable organic carbon and nitrogen isotopes in wetland soil of Poyang Lake and its environmental implications. China Environmental Science, 2016, 36(2): 500-505. [王毛兰, 赖建平, 胡珂图等. 鄱阳湖湿地土壤有机碳氮同位素特征及其环境意义. 中国环境科学, 2016, 36(2): 500-505.]

[19] Wang ML, Zhang DL, Lai JP et al. Distribution and sources of stable organic carbon and nitrogen isotopes in suspended particulate organic matter of Poyang Lake. China Environmental Science, 2014, 34(9) : 2342-2350. [王毛兰, 张丁苓, 赖建平等. 鄱阳湖水体悬浮有机质碳氮同位素分布特征及来源探讨. 中国环境科学, 2014, 34(9): 2342-2350.]

[20] Liang Y, Xiao H, Liu X et al. Spatial and temporal water quality characteristics of Poyang Lake Migratory Bird Sanctuary in China. Chinese of Journal Geochemistry, 2015, 34(1): 34-48.

[21] Hu CH, Huang D, Zhou WB et al. Study on Trophic status and influencing factors of typical lake fringe area in wet season A case study of Banghu Lake. Journal of Hydroecology, 2013, 34(3):32-38. [胡春华, 黄丹, 周文斌等. 典型湖泊边 缘区丰水期营养状态及其影响因子研究——以蚌湖为例. 水生态学杂志, 2013, 34(3) : 32-38.]

[22] Ministry of Environmental Protection of the People's Republic of China, Editorial Board of Water and Wastewater Monitoring and Analysis Methods ed. Water and wastewater monitoring and analysis methods: 4th edition. Beijing: China Environmental Science Press, 2002. [ 国家环境保护总局《水和废水监测分析方法》编委会. 水和废水监测分析方法:第 4 
版. 北京: 中国环境科学出版社, 2002.]

[23] Xiao HY, Liu CQ. Sources of nitrogen and sulfur in wet deposition at Guiyang, southwest China. Atmospheris Environment, 2002, 36: 5121-5130.

[24] Wu HY, Chen KL, Chen ZH et al. Evaluation for the ecological quality status of coastal waters in East China Sea using fuzzy integrated assessment method. Mar Pollut Bull, 2012, 64: 546-555.

[25] Xiao HY, Liu CQ. Identifying organic matter provenance in sediments using isotopic ratios in an urban river. Geochemical Journal, 2010, 44: 181-187.

[26] Sigleo AC, Macko SA. Carbon and nitrogen isotopes in suspended particles and colloids, Chesapeake and San Francisco estuaries, USA. Estuarine. Coastal and Shelf Science, 2002, 54: 701-711.

[27] Goni MA, Teixeira MJ, Perkey DW. Sources and distribution of organic matter in a river dominated estuary ( Winyah Bay, SC, USA). Estuarine, Coastal and Shelf Science, 2003, 57: 1023-1048.

[28] Liang Y, Liu XZ, Xiao HY et al. Impact of high water level fluctuations on stable isotopic signature of POM and source identification in a floodplain lake-Bang Lake (Poyang Lake). Environmental Earth Sciences, 2016, 75(3) : 1-12.

[29] Liu YL, Yu H, Xu J et al. Stable nitrogen isotope in aquatic macrophytes as an indicator of anthropogenic nitrogen inputs to Lake Taihu. J Lake Sci, 2015, 27(2) : 243-249. DOI: 10.18307/2015.0207. [刘勇丽, 余辉, 徐军等. 利用水生植 物氮同位素作为人为氮输人太湖的生物指标. 湖泊科学, 2015, 27(2) : 243-249.]

[30] Kendall C, Silva SR, Kelly VJ. Carbon and nitrogen isotopic compositions of particulate organic matter in four large river systems across the United States. Hydrological Processes, 2001, 15: 1301-1346.

[31] Marion GS, Dunbar RB, Mucciarone DA et al. Coral skeletal $\delta^{15} \mathrm{~N}$ reveals isotopic traces of an agricultural revolution. Marine Pollution Bulletin, 2005, 50: 931-944.

[32] Xie YX, Xiong ZQ, Xing GX et al. Assessment of nitrogen pollutant sources in surface waters of Taihu Lake region. Pedosphere, 2007, 17: 200-208.

[33] Zhao LJ, Yin L, Xiao HL et al. Isotopic evidence for the moisture origin and composition of surface runoff in the headwaters of the Heihe River basin. Chinese Science Bulletin, 2011, 56(4/5) : 406-415.

[34] Yoshikawa C, Abe H, Aita MN et al. Insight into nitrous oxide production processes in the western North Pacific based on a marine ecosystem isotopomer model. Journal of Oceanography, 2016, 72(3) : 491-508.

[35] Chang CCY, McCormick PV, Newman S et al. Isotopic indicators of environmental change in a subtropical wetland. Ecological Indicators, 2009, 5: 825-836.

[36] Li S, Liu C, Li J et al. Assessment of the sources of nitrate in the Changjiang River, China using a nitrogen and oxygen isotopic approach. Environmental Science and Technology, 2010, 44: 1573-1578.

[37] Kendall C. Tracing sources and cycling of nitrate in catchments. In: Kendall C, Mcdonnell J eds. Isotope tracers in catchment hydrology. Amsterdam: Elsevier, 1998: 519-576.

[38] Fan LJ, Zhao FH, Cheng C. Research advances in stable nitrogen isotope in water bodies. Chinese Journal of Applied Ecol$o g y, 2016,27$ (8) : 2699-2707. [范丽俊, 赵峰华, 程晨. 水体中氮稳定同位素的研究进展. 应用生态学报, 2016, $27(8): 2699-2707$.

[39] Li SL, Liu CQ, Xiao HY et al. Using $\delta^{15} \mathrm{~N}$ to assess groundwater nitrogen pollution in Guiyang. Geochimica, 2005,34 (3) : 257-262. [李思亮, 刘丛强, 肖化云等. $\delta^{15} \mathrm{~N}$ 在贵阳地下水氮污染来源和转化过程中的辨识应用. 地球化学, $2005,34(3)$ : 257-262.]

[40] Heaton T. Isotopic studies of nitrogen pollution in the hydrosphere and atmosphere: A review. Chemical Geology: Isotope Geoscience Section, 1986, 59: 87-102.

[41] Deutsch B, Voss M, Fischer H. Nitrogen transformation processes in the Elbe River: Distinguishing between assimilation and denitrification by means of stable isotope ratios in nitrate. Aquat Sci, 2009, 71(2): 228-237.

[42] Zhang CY, Zhang S, Li ZH et al. Nitrogen isotope discrimination the source of nitrate pollution of underground water in Shijiazhuang City. Advances in Earth Sciences, 2004, 19(2) : 183-191. [张翠云, 张胜, 李政红等. 用氮同位素技术判 别石家庄市地下水硝酸盐污染的来源. 地球科学进展, 2004, 19(2) : 183-191.]

[43] Mariotti A, Landreau A, Simon B. 15N isotope biogeochemistry and natural denitrification process in groundwater: Application to the chalk aquifer of northern France. Geochimica et Cosmochimica Acta, 1988, 52 : 1869-1878. 